\title{
VEGETAÇÃO DA ÁREA DE PROTEÇÃO AMBIENTAL JABOTITIUA-JATIUM. MUNICÍPIO DE VISEU, PARÁ, BRASIL.
}

\author{
João Ubiratan M. dos SANTOS ${ }^{1}$, Dário Dantas do AMARAL ${ }^{2}$, Inocêncio de Sousa \\ GORAYEB ${ }^{2}$, Maria de Nazaré do C. BASTOS ${ }^{2}$, Ricardo de S. SECCO², \\ Salustiano Vilar Costa NETO ${ }^{3}$, Denise Cristina Torres COSTA ${ }^{4}$
}

\begin{abstract}
RESUMO - A Área de Proteção Ambiental Jabotitiua-Jatium, localiza-se no município de Viseu, Nordeste do Pará, ocupando uma área de 14.25 ha, sendo criada através da lei municipal n. ${ }^{\circ} 002 /$ 98, de 07 de abril de 1998, visando a proteção de um trecho representativo e preservado do litoral paraense, abrigando um espetacular ninhal de guarás (Eudocimus ruber L.), ave costeira que encontra-se na lista oficial da fauna em extinção no Brasil. Objetivando auxiliar o plano de manejo ambiental desta APA, o estudo em questão identificou quatro tipos de ambientes, classificados em Mangue, Campo Natural, Floresta Mista com Palmeiras e Restinga. Utilizandose a metodologia da Avaliação Ecológica Rápida (AER), foi identificado um total de 141 espécies, representantes de 61 famílias. $\mathrm{O}$ maior número de espécies corresponde à Floresta Mista com Palmeiras, apresentando 66 representantes, e a menor representatividade diz respeito ao mangue, com apenas quatro espécies. Fabaceae (15), Cyperaceae (10) e Rubiaceae (10), destacaram-se em número de espécies, correspondendo, juntas, a $24,82 \%$ do total das espécies registradas. As ervas representam a maioria (48) quanto a forma de vida, seguida dos arbustos (38), árvores (34), Lianas (13), estipe (5) e epífitos (3).
\end{abstract}

Palavras-chave: Ecossistema litorâneo, Florística, Avaliação Ecológica Rápida, Área de Proteção Ambiental.

\section{Vegetation of the Jabotitiua-Jatium Protected Environmental Area, municipality of Viseu, Pará, Brazil}

\begin{abstract}
The Jabotitiua-Jatium Protected Area comprises 14.25 ha in the Municipal District of Viseu in northeast Pará. The area was established by municipal law 002/98 on 7 April 1998 in order to protect a representative sample of coastal Amazonia, including an important nesting site of the endangered scarlet ibis (Eudocimus ruber L.). The objective of this study was to provide floristic information useful for developing a management plan for the area. Four habitat types were found to occur in the area: mangrove, savanna?, mixed palm-forest, and sandy coastal. A Rapid Ecological Assessment (AER) of the area identified 141 species of angiosperms in 61 families. The mixed palm-forest, with 66 species, is the most species-rich habitat. Only four species occur in the mangrove, the most depauperate habitat. The three dominant families are the Fabaceae (15 spp.), Cyperaceae (10 spp.), and Rubiaceae (10 spp.), which, combined, account for $24.82 \%$ of the total species occurring in the protected area. Forty-eight species are terrestrial herbs, 38 shrubs, 34 trees, 13 lianas, 5 stem, and 3 epiphytes.
\end{abstract}

Key-words: Coastal ecosystem, Floristics, Rapid Ecological Assessment, Protected Environmental Area.

\section{INTRODUÇÃO}

As planícies costeiras do Brasil são consideradas, de acordo com a Constituição Federal vigente, patrimônio nacional, constando do Artigo 225, parágrafo 4. Constituem um ambiente de produção primária extremamente complexo, dada às condições ambientais que estão sujeitas e à fragilidade do meio às perturbações antrópicas, como a especulação

${ }^{1} \mathrm{MEC}$ / Faculdade de Ciências Agrárias do Pará - FCAP

${ }^{2} \mathrm{MCT}$ / Museu Paraense Emílio Goeldi - Belém, PA

${ }^{3}$ IEPA - Instituto Estadual de Pesquisa do Amapá

${ }^{4} \mathrm{CNPq} / \mathrm{MPEG}$ - Bolsista DCR 
imobiliária, turismo predatório, retirada de madeira, extração de areia para fins de construção civil e extrativismo animal.

A vegetação costeira do Pará, especialmente a do litoral Nordeste do Estado, vem sendo estudada ao longo dos anos, com investigações, em sua maioria, sobre composição florística, fitossociologia e taxonomia (Santos \& Rosário, 1988; Bastos et al., 1995; Bastos, 1996; Amaral, 1997; Amaral, 2001; Costa Neto, 1995; Costa Neto, 2001).

Dentre os ecossistemas naturais predominantes neste litoral, destacam-se os manguezais, as restingas, os campos naturais e remanescentes de florestas primárias. Com vistas ao equilíbrio ambiental destas áreas, local de abrigo, reprodução e fonte de alimento da fauna ocorrente, particularmente os guarás (Eudocimus ruber L.), criou-se no município de Viseu, local deste estudo, através do apoio de estudiosos do assunto, a área de proteção ambiental Jabotitiua-Jatium, através da lei municipal n. ${ }^{\circ}$ 002/98, de 07 de abril de 1998. criação desta unidade de conservação foi proposta por pesquisadores do Museu Paraense Emílio Goeldi e da Universidade Federal do Pará após viagens de estudos técnicos científicos à costa de Viseu, organizada e coordenada por I. S. Gorayeb.

Objetivando adicionar conhecimentos sobre os ecossistemas costeiros do Estado, em particular contribuindo com o plano de manejo ambiental da Área de Proteção Ambiental Jabotitiua-Jatium., o presente estudo volta-se à uma caracterização dos tipos de vegetação ocorrentes no local. O estudo é também básico para o processo de exploração auto-sustentável dos recursos naturais litorâneos, com maior participação das comunidades tradicionais costeiras, organizadas em reservas extrativistas, na gestão biorregional do Corredor Ecológico da Zona Costeira Paraense.

\section{MATERIAIS E MÉTODOS}

\section{Área de Estudo}

A Área de Proteção Ambiental Jabotitiua-Jatium, pertence ao Município de Viseu, situado no litoral Nordeste do Pará, distando de Belém aproximadamente $300 \mathrm{~km}$ (Figura 1).
Compreende uma área de $14.253,8$ ha. Inclui ao norte a ilha Jatium, a leste a ilha dos Pássaros. A ilha Jatium abrange 1.357,8 ha, distando cerca de $2 \mathrm{~km}$ em linha reta de Viseu. Destaca-se na região a ilha dos Pássaros com $1.023,9 \mathrm{ha}$, considerado um local especial, abrigando um ninhal de guarás (Eudocimus ruber L.), espécie de pássaros costeiros que consta na lista oficial de animais em extinção.

Fazendo parte do litoral nordeste do Estado, a referida área apresenta, de maneira geral, segundo Prost (1994), o substrato geológico formado na base por rochas originadas no pré-cambriano, que afloram justamente nesta região próxima à desembocadura do Gurupí-MA.

\section{Amostragem da Vegetação}

Com base em imagem de satélite (LANDSAT), bem como, informações e observações de campo, selecionaram-se trechos representativos dos diferentes ambientes constituintes da APA, para fins de amostragem da vegetação.

A amostragem baseou-se nos procedimentos de Avaliação Ecológica Rápida (AER), um protocolo para inventário florístico qualitativo baseado em Pontos de Observação (PO's) desenvolvido pela The Nature Conservancy (TNC, 1992). Os PO's são áreas pontuais com raio de $25 \mathrm{~m}$ onde são registradas todas as plantas. A cada espécie foi atribuída, de forma subjetiva, uma ocorrência ou densidade, podendo ser: Abundante - espécies cujas populações são muito numerosas e que chegam a formar manchas ou agregados monoespecíficos; Comum - espécies também numerosas porém não formando agregados; Ocasional - espécies cujo padrão de ocorrência assemelha-se àquele esperado ao acaso; Raro espécies que ocorrem em baixas densidades, com 1 indivíduo por Ponto de Observação (PO).

Realizaram-se 02 pontos de observação (PO) em cada ambiente da APA. Utilizando-se uma imagem do satélite LANDSAT, tratada no programa ARC VIEW, demarcaram-se todas as tipologias vegetais, obtendo-se informações sobre tamanho e perímetro das mesmas . A classificação dos vegetais foi baseada no sistema de Cronquist (1981). Todo o material botânico coletado encontra-se depositado no herbário do Museu Paraense Emílio Goeldi. 


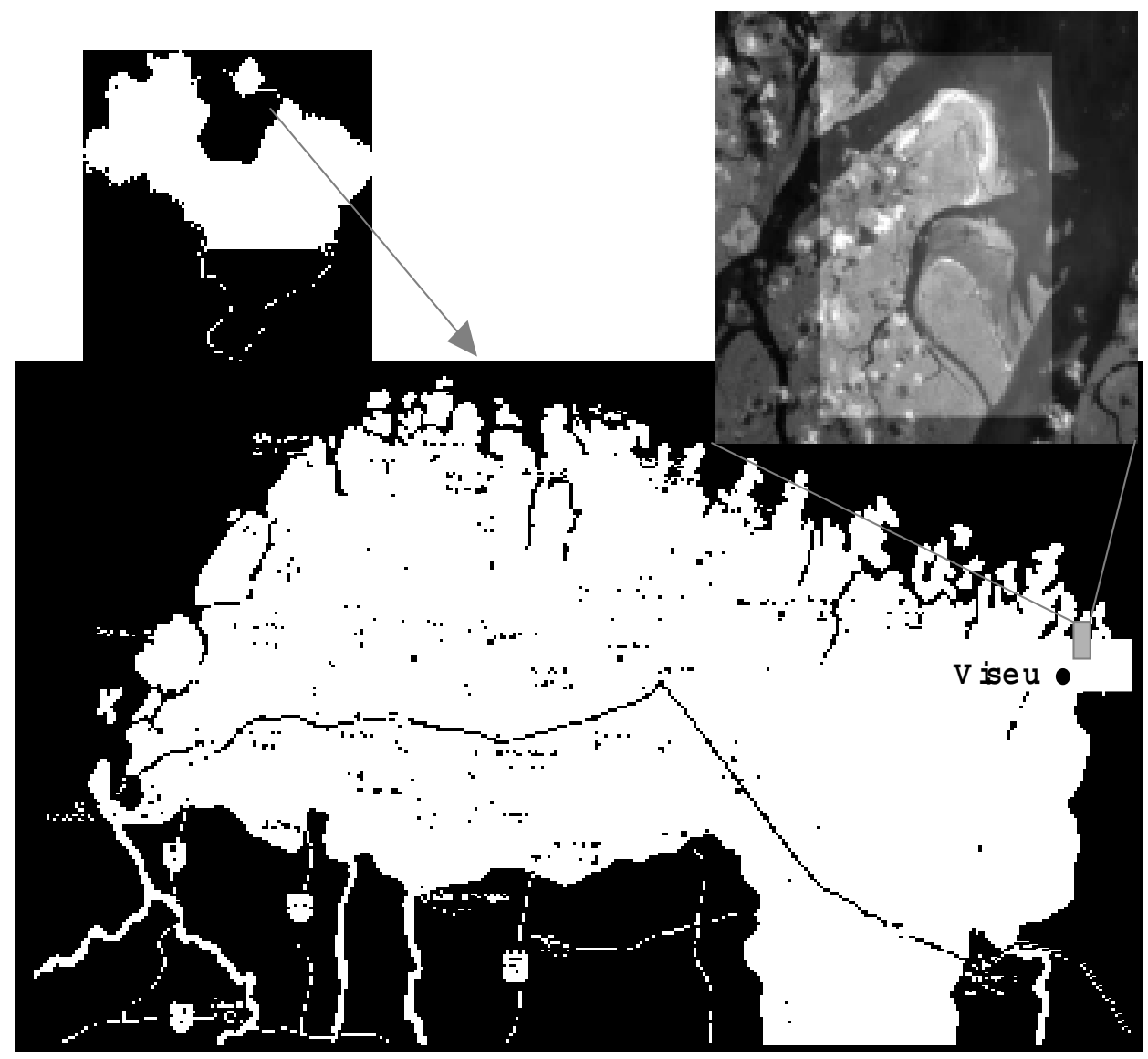

Figura 1 - Localização da área de estudo. Área de Proteção Ambiental Jabotitiua-Jatium, município de Viseu, Pará, Brasil.

\section{RESULTADOS E DISCUSSÃO}

A APA Jabotitiua-Jatium abrange quatro tipos de vegetação, classificados em manguezal, correspondendo a maior fisionomia da área, com 6.584 ha, seguido pelo campo natural com 684 ha, posteriormente a restinga com 198 ha, e em menor dimensão a floresta mista com palmeiras, com 171 ha.

Nos quatro tipos de vegetação, listouse um total de 141 espécies, distribuídas 61 famílias. A Tabela 1 apresenta a listagem das espécies e respectivas famílias, relacionandoas com o ambiente encontrado, a forma de crescimento e estimativa de densidade relativa das mesmas. A maior riqueza específica corresponde à floresta mista com palmeiras, apresentando 69 espécies exclusivas desta tipologia, seguida pela restinga com 36 representantes, posteriormente o campo com 23 espécies e por último o manguezal, apresentando 04 espécies. Outras 09 espécies ocorrem em 02 ou mais ambientes. Destacaramse em riqueza de espécies as famílias Fabaceae (15), Cyperaceae (10) e Rubiaceae (10), além de Caesalpinaceae (6), Arecaceae (5), Chrysobalanaceae (5) e Poaceae (5), correspondendo, juntas, a $36,17 \%$ do total das espécies registradas. As outras 54 famílias apresentaram menos de cinco espécies cada. 
Tabela 1 - Listagem florística da Área de Proteção Ambiental Jabotitiua-Jatium, com indicação de famílias, ambiente encontrado, forma de crescimento e estimativa de densidade. Município de Viseu, Pará, Brasil.

\begin{tabular}{|c|c|c|c|c|c|}
\hline & ESPÉCIE & FAMÍLIA & AMBIENTE & $\begin{array}{l}\text { FORMA DE } \\
\text { CRESCIMENTO }\end{array}$ & DENSIDADE \\
\hline 1 & Aeschynomene evenia C. Wright ex Sauvalle & Fabaceae & Campo & Erva & Abundante \\
\hline 2 & Alibertia edulis A. Rich. & Rubiaceae & Floresta & Arbusto & Comum \\
\hline 3 & Alibertia myrciifolia Schum. & Rubiaceae & Floresta & Arbusto & Comum \\
\hline 4 & Alternanthera tenella Colla & Amaranthaceae & Restinga & Erva & Abundante \\
\hline 5 & Amasonia campestris (Aubl.) Moldenke & Verbenaceae & Floresta & Erva & Ocasional \\
\hline 6 & Ambrosia microcephala DC. & Asteraceae & Restinga & Erva & Abundante \\
\hline 7 & Andira retusa (Lam.) H.B.K & Fabaceae & Floresta & Árvore & Ocasional \\
\hline 8 & Annona glabra L. & Annonaceae & Restinga & Arbusto & Comum \\
\hline 9 & Astrocaryum vulgare Mart. & Arecaceae & Floresta & Estipe & Abundante \\
\hline 10 & Astyposanthes gracili 's (Kunth) Herter & Fabaceae & Campo & Erva & Comum \\
\hline 11 & Attalea speciosa Mart. & Arecaceae & Floresta & Estipe & Abundante \\
\hline 12 & Avicennia germinans (L.) L. & Verbenaceae & Mangue & Árvore & Abundante \\
\hline 13 & Banara guianensis Aubl. & Flacourtiaceae & Floresta & Árvore & Ocasional \\
\hline 14 & Bauhinia guianensis Aubl. & Caesalpinaceae & Floresta & Liana & Comum \\
\hline 15 & Blutaparon portulacoides (A. St.-Hil.) Miars & Amaranthaceae & Restinga & Erva & Abundante \\
\hline 16 & Borreria sp & Rubiaceae & Restinga & Erva & Abundante \\
\hline 17 & Brosimum guianense (Aubl.) Huber & Moraceae & Floresta & Arbusto & Ocasional \\
\hline 18 & Byrsonima crassifolia (L.) Kunth & Malpighiaceae & Campo, Restinga & Arbusto & Comum \\
\hline 19 & Caesalpinia bracteosa Tul. & Caesalpinaceae & Floresta & Arbusto & Ocasional \\
\hline 20 & Canavalia rosea (Sw.) DC. & Fabaceae & Restinga & Erva & Abundante \\
\hline 21 & Casearia javitensis Kunth & Flacourtiaceae & Floresta & Arbusto & Ocasional \\
\hline 22 & Cassia fastuosa Willd. ex Vogel & Caesalpinaceae & Restinga & Árvore & Comum \\
\hline 23 & Cassita americana Nees & Lauraceae & Campo & Liana & Abundante \\
\hline 24 & Catasetum discolor (Lindl.) Lindl. & Orchidaceae & Restinga & Epífito & Ocasional \\
\hline 25 & Cecropia distachya Huber & Cecropiaceae & Floresta & Árvore & Ocasional \\
\hline 26 & Ceiba pentandra (L.) Gaertn. & Bombacaceae & Floresta & Árvore & Raro \\
\hline 27 & Chamaecrista diphylla (L.) Greene & Caesalpinaceae & Campo & Erva & Ocasional \\
\hline 28 & Cheiloclinium cognatum (Miers.) A.C. Smith & Hippocrateaceae & Floresta & Arbusto & Ocasional \\
\hline 29 & Chrysobalanus icaco L. & Chrysobalanaceae & Campo & Arbusto & Abundante \\
\hline 30 & Connarus angustifolius (Radlkofer) G. Schellenb. & Connaraceae & Floresta & Arbusto & Ocasional \\
\hline 31 & Conocarpus erectus $\mathrm{L}$. & Combretaceae & Mangue & Arbusto & Abundante \\
\hline 32 & Couepia ovalifolia (Schott) Benth. ex Hook. f. & Chrysobalanaceae & Floresta & Arbusto & Ocasional \\
\hline 33 & Crotalaria falcata Schumach. \& Thonn. & Fabaceae & Restinga & Arbusto & Comum \\
\hline 34 & Crotalaria retusa L. & Fabaceae & Restinga & Arbusto & Comum \\
\hline 35 & Cupania diphylla Vahl & Sapindaceae & Floresta & Árvore & Comum \\
\hline 36 & Cuphea flava Spreng. & Lythraceae & Restinga & Erva & Comum \\
\hline 37 & Cyperus haspan L. & Cyperaceae & Restinga, Campo & Erva & Abundante \\
\hline 38 & Cyperus ligularis L. & Cyperaceae & Campo & Erva & Abundante \\
\hline 39 & Cyperus luzulae (L.) Rottb. ex Retz. & Cyperaceae & Floresta & Erva & Comum \\
\hline 40 & Dalbergia ecastaphyllum (L.) Taub. & Fabaceae & Restinga & Liana & Abundante \\
\hline 41 & Desmodium barbatum (L.) Benth. & Fabaceae & Campo & Erva & Comum \\
\hline 42 & Desmoncus orthacanthos Mart. & Arecaceae & Campo, Floresta & Estipe & Ocasional \\
\hline 43 & Diodia ocymifolia (Willd. ex Roem. \& Schult.)Bremek. & Rubiaceae & Restinga & Erva & Ocasional \\
\hline 44 & Distictella racemosa (Bureau \& K. Sch.) Urb. & Bignoniaceae & Restinga & Liana & Ocasional \\
\hline 45 & Dodonaea viscosa Jacq. & Sapindaceae & Restinga & Arbusto & Ocasional \\
\hline 46 & Doliocarpus dentatus (Aubl.) Standl. & Dilleniaceae & Floresta & Liana & Comum \\
\hline
\end{tabular}


Tabela 1 - Continuação

\begin{tabular}{|c|c|c|c|c|c|}
\hline 47 & Drymonia coccinea (Aubl.) Wiechler & Gesneriaceae & Floresta & Epífito & Ocasional \\
\hline 48 & Duguetia echinophora R.E. Fries & Annonaceae & Floresta & Árvore & Comum \\
\hline 49 & Eleocharis geniculata (L.) Roem. \& Schult. & Cyperaceae & Campo & Erva & Abundante \\
\hline 50 & Emilia sonchifolia (L.) DC. & Asteraceae & Restinga & Erva & Ocasional \\
\hline 51 & Entada polyphylla Benth. & Mimosaceae & Restinga, Floresta & Liana & Comum \\
\hline 52 & Erythroxylum micranthum Bong. ex. Peyr. & Erytroxylaceae & Floresta & Arbusto & Comum \\
\hline 53 & Eschweilera coriacea (DC.) S.A. Mori & Lecythidaceae & Floresta & Árvore & Comum \\
\hline 54 & Eugenia biflora (L.) DC. & Myrtaceae & Campo & Arbusto & Comum \\
\hline 55 & Fagara rhoifolia (Lam.) Engl. & Rutaceae & Floresta & Árvore & Ocasional \\
\hline 56 & Faramea crassifolia Benth. & Rubiaceae & Floresta & Arbusto & Comum \\
\hline 57 & Fimbristylis cymosa $\mathrm{R}$. Br. & Cyperaceae & Restinga & Erva & Abundante \\
\hline 58 & Fimbristylis spadicea (L.) Vahl & Cyperaceae & Restinga & Erva & Abundante \\
\hline 59 & Funastrum clausum (Jacq.) Schl & Asclepiadaceae & Restinga & Liana & Comum \\
\hline 60 & Guapira opposita (Vell.) Reitz & Nyctaginaceae & Floresta & Arbusto & Comum \\
\hline 61 & Guatteria schomburgkiana Mart. & Annonaceae & Floresta & Árvore & Comum \\
\hline 62 & Gustavia augusta L. & Lecythidaceae & Floresta & Árvore & Comum \\
\hline 63 & Habenaria longipedicellata Hoehne & Orchidaceae & Campo & Erva & Comum \\
\hline 64 & Heisteria ovata Benth. & Olacaceae & Floresta & Arbusto & Comum \\
\hline 65 & Heliconia psittacorum L.f. & Heliconiaceae & Floresta, Campo & Erva & Comum \\
\hline 66 & Heliotropium polyphyllum Lehem. & Boraginaceae & Restinga & Erva & Abundante \\
\hline 67 & Heteropterys nervosa A.Juss. & Malpighiaceae & Restinga & Liana & Ocasional \\
\hline 68 & Hirtella eriandra Benth. & Chrysobalanaceae & Floresta & Arbusto & Comum \\
\hline 69 & $\begin{array}{l}\text { Hirtella racemosa var. hexandra (Willd. ex } \\
\text { Roem. \& Schult.) Prance }\end{array}$ & Chrysobalanaceae & Floresta & Arbusto & Comum \\
\hline 70 & Hymenaea parvifolia Huber & Caesalpinaceae & Floresta & Árvore & Ocasional \\
\hline 71 & Hyptis atrorubens Poit. & Lamiaceae & Campo & Liana & Abundante \\
\hline 72 & Indigofera anil L. & Fabaceae & Campo & Erva & Ocasional \\
\hline 73 & Inga fagifolia G. Don. & Mimosaceae & Restinga & Arbusto & Ocasional \\
\hline 74 & Inga thibaudiana DC. & Mimosaceae & Floresta & Árvore & Comum \\
\hline 75 & Ipomoea littoralis (L.) Choisy & Convolvulaceae & Restinga & Erva & Comum \\
\hline 76 & Kyllinga peruviana Lam. & Cyperaceae & Campo & Erva & Comum \\
\hline 77 & Laguncularia racemosa Gaert. & Combretaceae & Mangue & Árvore & Abundante \\
\hline 78 & $\begin{array}{l}\text { Licania octandra (Hoffmanns. ex Roem. \& } \\
\text { Schult.) Kuntze }\end{array}$ & Chrysobalanaceae & Floresta & Arbusto & Comum \\
\hline 79 & Ludwigia hyssopifolia (G. Don) Exell & Onagraceae & Campo & Erva & Abundante \\
\hline 80 & Machaerium lunatum (L.f.) Ducke & Fabaceae & Restinga & Arbusto & Abundante \\
\hline 81 & Matayba guianensis Aubl. & Sapindaceae & Floresta & Árvore & Comum \\
\hline 82 & Maximiliana maripa (C. Serra) Drude & Arecaceae & Floresta & Estipe & Comum \\
\hline 83 & Melochia hirsuta Cav. & Sterculiaceae & Restinga & Erva & Comum \\
\hline 84 & Memora flavida (DC.) Bureau \& K. Schum. & Bignoniaceae & Floresta & Liana & Comum \\
\hline 85 & Miconia flavida Cog. ex Standl. & Melastomataceae & Floresta & Arbusto & Ocasional \\
\hline 86 & Mikania congesta DC. & Asteraceae & Campo & Liana & Abundante \\
\hline 87 & Mouriri acutiflora Naudin & Memecilaceae & Floresta & Árvore & Ocasional \\
\hline 88 & Mouriri guianensis Aubl. & Memecilaceae & Floresta & Arbusto & Comum \\
\hline 89 & Muellera frutescens (Aubl.) Standl. & Fabaceae & Restinga & Erva & Ocasional \\
\hline 90 & Myrcia bracteata (Rich.) DC. & Myrtaceae & Floresta & Arbusto & Ocasional \\
\hline 91 & Myrcia cuprea (O.Berg) Kiaersk. & Myrtaceae & Campo & Arbusto & Comum \\
\hline 92 & Myrcia fallax (Rich.) DC. & Myrtaceae & Floresta & Arbusto & Comum \\
\hline 93 & Nymphaea gardneriana Planch. & Nymphaeaceae & Campo & Erva & Comum \\
\hline 94 & Nymphoides indica (L.) Kuntze & Menyanthaceae & Campo & Erva & Comum \\
\hline
\end{tabular}




\section{Tabela 1 - Continuação}

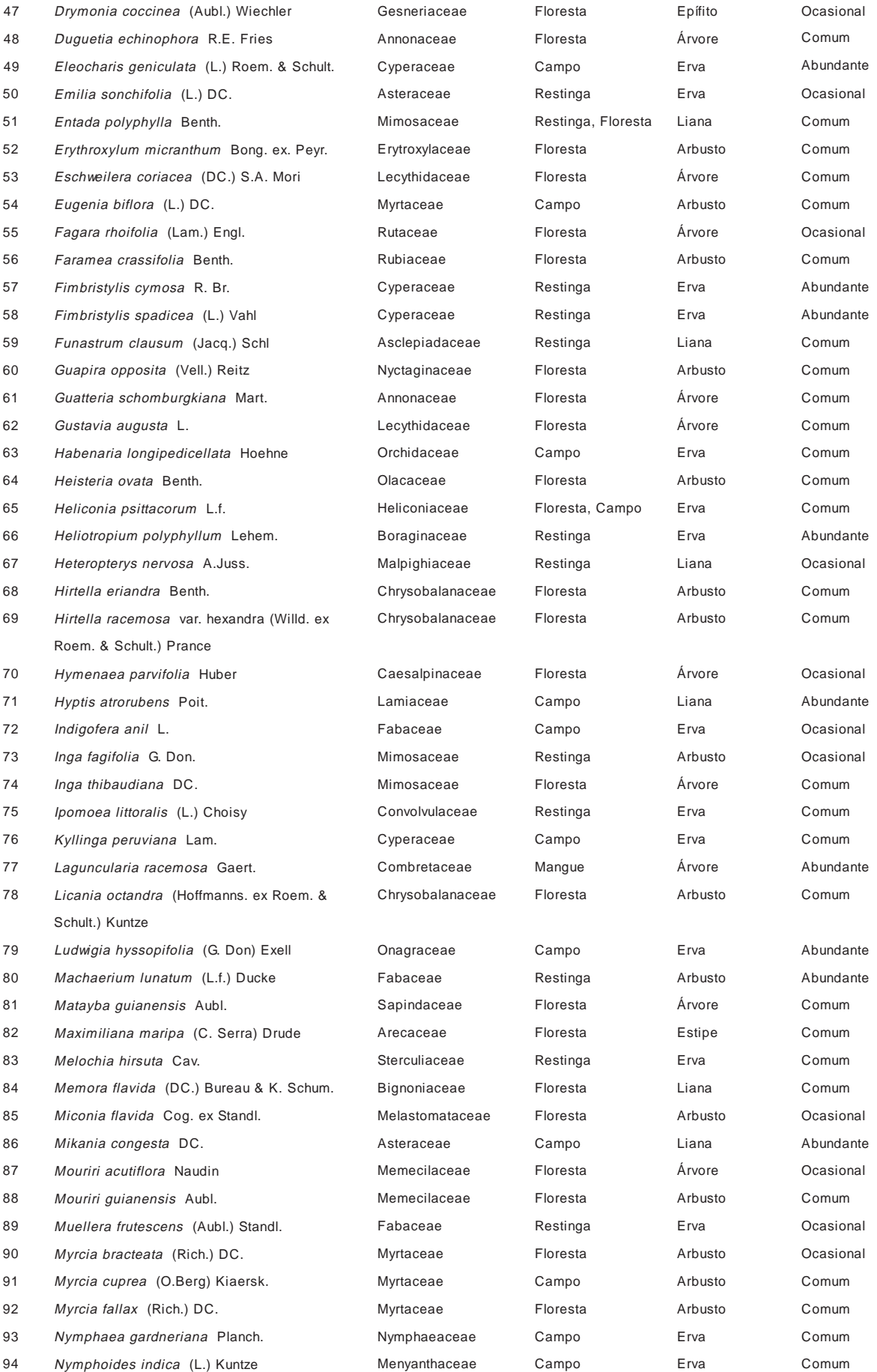


Descreve-se, a seguir, as principais características de cada ambiente, as espécies mais expressivas, bem como discussões relacionadas aos mesmos.

\section{Manguezal}

Correspondendo à maior fisionomia vegetal da APA (6.584 ha), o manguezal destacase pela exuberância de seus bosques, com altura dos indivíduos, no trecho amostrados, variando entre $15-20 \mathrm{~m}$, com emergentes de $25 \mathrm{~m}$ (Figura 2).

Segundo Scheffer-Novelli \& Cintrón (1988) os manguezais estão distribuídos no Brasil desde o paralelo $4^{\circ} 20^{\prime} \mathrm{N}$ até o paralelo $28^{\circ} 30^{\prime} \mathrm{S}$, estendendo-se desde o Cabo Orange, no Amapá, até a cidade de Santa Catarina, sendo representados por bosques, com características estruturais bem variadas.

No Pará os manguezais ocupam uma área estimada em 2,9 mil km² (IBDF, 1988), com ocorrência desde a foz do rio Amazonas, onde o aporte de água doce no contato com o oceano é intenso, até o litoral Nordeste do Estado, havendo aí considerável redução no volume de água doce.
A vegetação do manguezal estudado é representada por Rhizophora mangle, Avicennia germinans, Laguncularia racemosa e Conocarpus erectus, comuns, de maneira geral, ao longo de todo o litoral paraense (Almeida \& Lobato, 1990; Bastos \& Lobato, 1996). Detectou-se uma maior concentração de Rhizophora mangle e Avicennia germinans, em detrimento à Laguncularia racemosa, freqüente nas porções mais externas do mangue. A ocorrência de Conocarpus erectus restringe-se às áreas de contato com a restinga.

Numa análise florística dos manguezais do Pará, Almeida (1996) sugere uma relação de padrões de densidade de indivíduos e riqueza de espécies vinculados a teores de nutrientes e salinidade do ambiente, numa análise de que quanto mais próximo do estuário, menor o estress salino, maior a disponibilidade de nutrientes via descarga do rio Pará e portanto maior a possibilidade de colonização vegetal. Não obstante a esta interpretação, deve-se, obviamente, considerar as idades dos manguezais, assim como as particularidades geomorfológicas onde estes se encontram.

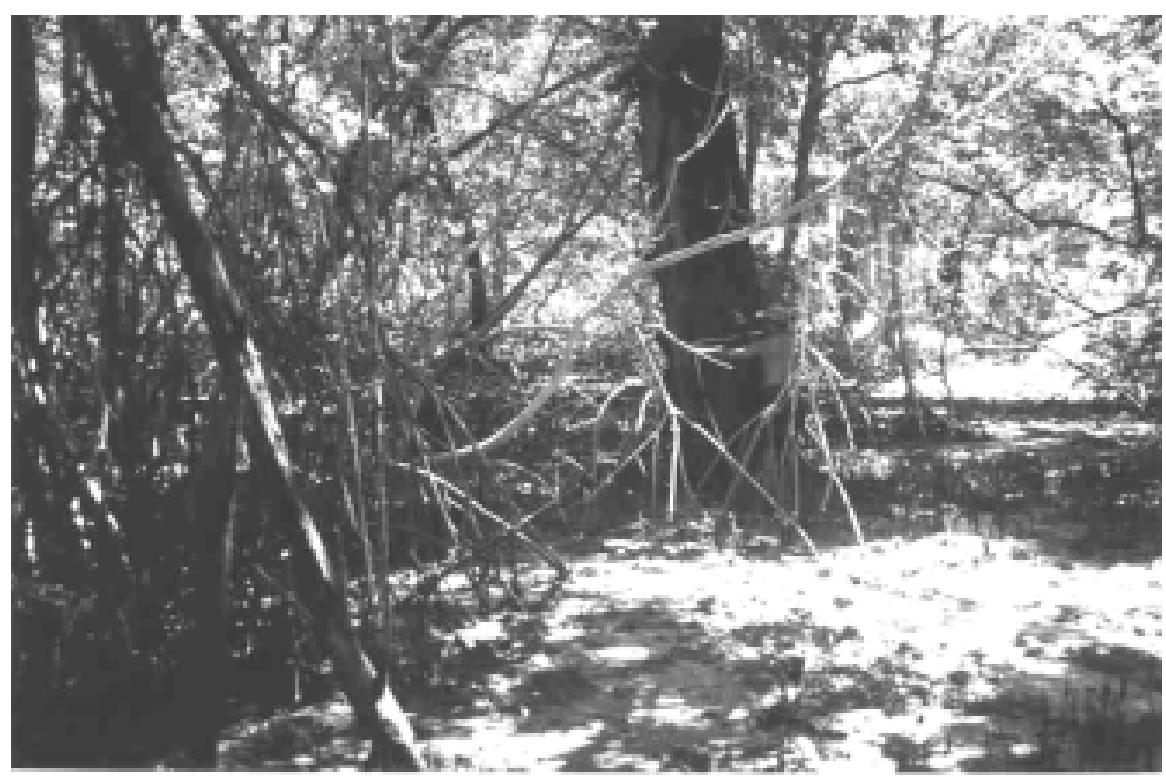

Figura 2 - Vista geral do manguezal. Área de Proteção Ambiental Jabotitiua-Jatium, município de Viseu, Pará, Brasil. 
Em estudo realizado nos manguezais de Salvaterra - Marajó, Pará, Lisboa et al, (1993) registraram a presença de uma espécie não comum à região deste estudo, a Rhizophora racemosa G.F.W. Meyer, que, segundo os autores, apresenta distribuição desde o hemisfério Norte das Américas, chegando ao estuário do Amazonas, prolongando-se até os arredores do município de Colares, no litoral Nordeste do Pará. Tal espécie, em conjunto com Avicennia germinans foram as mais representativas no local, sendo A. germinans, superior em dominância, fato também verificado por Almeida \& Lobato (1990) para diversos manguezais do litoral paraense. No presente estudo, embora não tenham sido registrados dados estruturais, observou-se a maior expressividade dessa espécie em relação às demais, tanto em altura total quanto em diâmetro.

\section{Campos naturais}

Este tipo de ambiente ocorre nas porções centrais da APA, representando uma área 684 ha. Ocupam diferentes extensões, sendo constituídos, na sua maioria, por uma vegetação herbácea, principalmente Cyperaceae, como Eleocharis geniculata, Rhynchospora holoschoenoides e Cyperus haspan. Esses ambientes são geralmente limitados pelas florestas mistas com palmeiras (Figura 3).

No interior dos campos formam-se ilhas de vegetação, de tamanhos reduzidos, com predominância de espécies arbustivas, principalmente Caesalpinia sp., Eugenia biflora, Sapium curupita e Ouratea racemiformis. Comuns nesta paisagem, é a ocorrência de lagos temporários, principalmente nas áreas de baixios, regidos pelo regime pluviométrico local. Nessas lagos ocorrem algumas macrófitas aquáticas, como Nymphoides indica e Nymphaea gardneriana. Em alguns trechos, no contato com o manguezal, existem áreas denominadas de apicuns, definidas como zonas hipersalinas, com cobertura herbácea, dominada por Sporobolus virginicus e arbustos como Conocarpus erectus, Laguncularia racemosa, e Avicennia germinans.

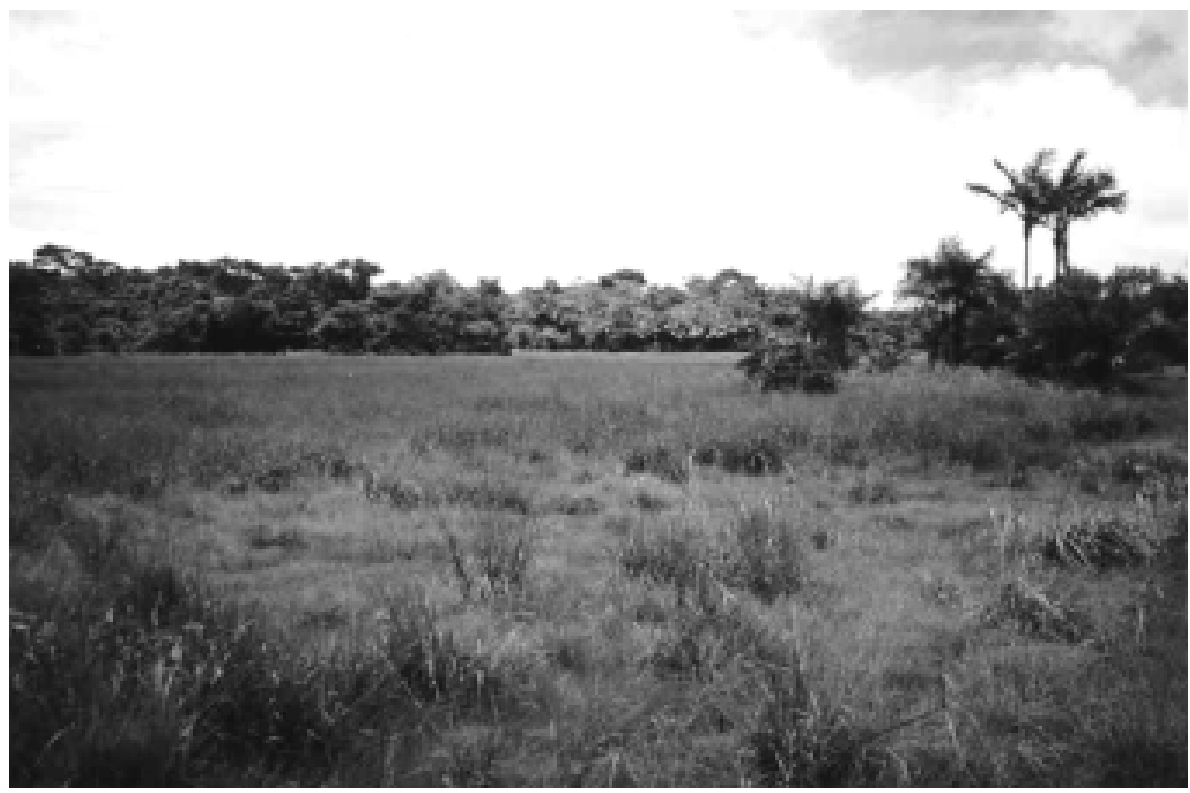

Figura 3 - Vista geral dos campos naturais. Área de Proteção Ambiental Jabotitiua-Jatium, município de Viseu, Pará, Brasil. 
Segundo Pires (1973) a Amazônia possui uma área não florestal com $150.000 \mathrm{~km}^{2}$, onde, aproximadamente $12 \%$ correspondem ao arquipélago do Marajó. $\mathrm{O}$ autor denomina os campos daquela região de Campos Cobertos, caracterizando-os como interrupções da floresta alta, apresentando uma conspícua vegetação de Gramineae enchendo o espaço livre entre as plantas lenhosas, como acontece com os cerrados do Brasil Central.

Bastos (1984) estudou os campos de Joanes, na Ilha do Marajó, cujas descrições fisionômicas do ambiente são bastante semelhantes aos campos do presente estudo. Em termos de composição florística, a semelhança é reduzida, representada pelas espécies Desmodium barbatum e Psychotria barbiflora.

Dentre as arbustivas e arbóreas figuram Byrsonima crassifolia, Myrcia cuprea, Vismia guianensis, Protium heptaphyllum, Virola sebifera, Ouratea castaneifolia e Alibertia myrciifolia.

Ainda na região marajoara, no trecho entre os rios Anajás e Atuá, foi realizada uma caracterização da fitoecologia e da flora local (Relatório Técnico - MPEG, 1998), onde os campos naturais foram subdivididos em 04 tipos diferentes de acordo com aspectos fisionômicos e florísticos, classificados em Campo Misto com Palmeiras, Campo Arbustivo-Arbóreo, Campo HerbáceoGraminoso e Campo Inundável Baixo. O estudo supõe que a origem e manutenção desta paisagem deva-se ao controle edáfico e hidrológico, especialmente o regime de enchentes a que estão submetidos esses campos anualmente, no referido local. Traçando analogias, os campos de Viseu apresentam maiores semelhanças com o tipo Campo Arbustivo-Arbóreo daquele local, com espécies herbáceas coincidentes como Cyperus luzulae, Hyptis atrorubens e Ludwigia hyssopifolia, além das arbustivas Paullinia pinnata, Simarouba amara, Inga thibaudiana, entre outras.

\section{Floresta mista com palmeiras}

Ocorrem geralmente em alternância com as áreas de campo, ocupando locais onde o relevo é mais elevado, constituindo-se em manchas de tamanhos variados, totalizando 171 ha. (Figura 4).

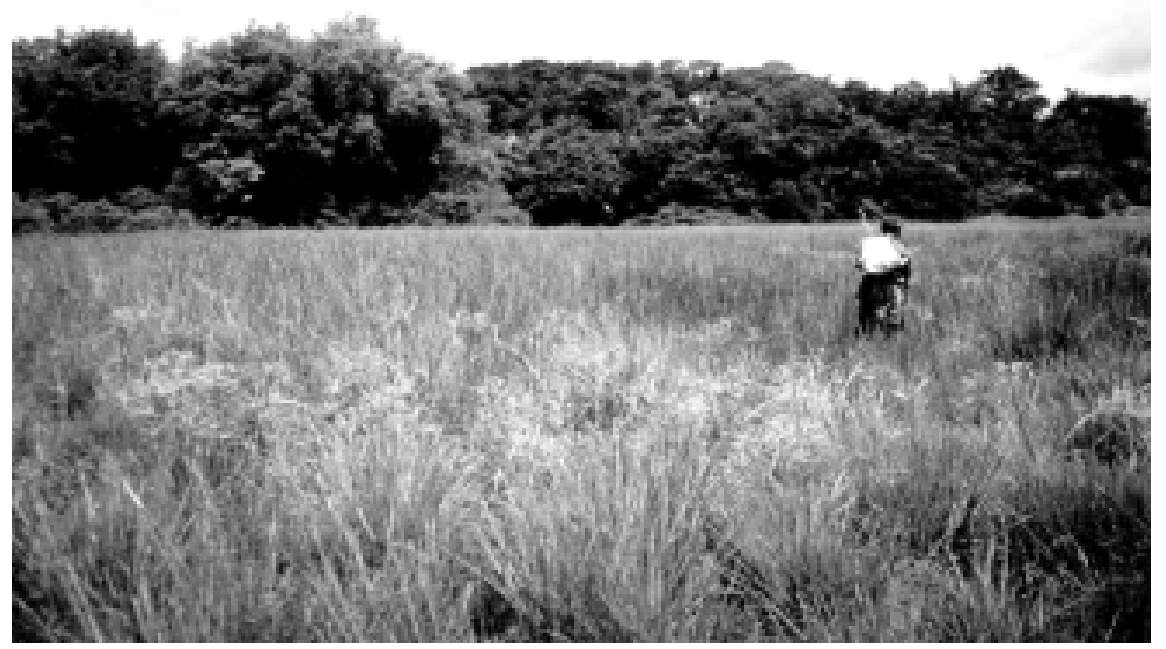

Figura 4 - Vista geral da floresta mista com palmeiras (ao fundo), limitada com o campo (primeiro plano). Área de Proteção Ambiental Jabotitiua-Jatium, município de Viseu, Pará, Brasil. 
No ponto amostral, a floresta encontrase sobre um solo arenoso, apresentando uma camada superficial de matéria orgânica, bastante reduzida, não ultrapassando a $3 \mathrm{~cm}$ de espessura. São comuns afloramentos pontuais de rochas quartzosas. A fisionomia é marcada pela presença de palmeiras, principalmente Astrocaryum vulgare (Tucumã) e Maximiliana maripa (Inajá), com destaque para Attalea speciosa (babaçú) nas áreas de contato com o campo. A entrada de luz no ambiente é elevada, favorecida pela copa das árvores, geralmente pouco densas, o que deve influir no baixo grau de epifitismo local e em parte, no sucesso na regeneração de palmeiras, geralmente exigentes em luz.

Os indivíduos apresentam altura entre 10-15 m, com alguns emergentes de $20 \mathrm{~m}$, entre as quais Parkia pendula e Qualea albiflora Destacam-se em densidade relativa Heisteria ovata, Alibertia myrciifolia, Simarouba amara, Cupania diphylla, Randia armata, Myrcia fallax e Hirtella hexandra. As lianas mais comuns são Bauhinia guianensis, Doliocarpus dentatus., Miconia flavida e Sipanea aspera.

Em região estuarina, na Ilha do Marajó, Lisboa et al (1993) amostraram uma área florestal, denominando-a de floresta alta aberta com palmeiras. Das 96 espécies citadas no trabalho, 18 são comuns à floresta em questão, como Maximiliana maripa, Asrtocarym vulgare, Eschweilera coriacea, Virola sebifera, Andira retusa e Matayba guianensis.

A floresta mista com palmeiras investigada no Marajó (Relatório Técnico, MPEG, 1998) embora ocorrendo em região geográfica distinta da área deste estudo, sob condições ambientais diferentes, principalmente pluviometria e pedologia, apresentam semelhanças florísticas e fisionômicas, marcada principalmente pela presença de palmeiras, como Maximiliana maripa e Astrocaryum vulgare, Desmoncus orthacanthus e as arbustivas/arbóreas Casearia javitensis, Eschweilera coriacea, Hymenaea parviflora, Licania octandra, Swartzia laurifolia, além de vários gêneros como Andira, Vismia, Virola, Qualea, Annona, Hymenaea, Eugenia e Protium.

\section{Restinga}

A vegetação de restinga ocorre na área em estudo atingindo 198 ha (Figura 5), ocupando dimensões variadas no sentido marcontinente, com trechos de até $300 \mathrm{~m}$ de comprimento. $\mathrm{O}$ ambiente está representado por três formações vegetais, denominadas de halófila, psamófila reptante e brejo herbáceo (Araújo \& Henriques, 1984), distribuídas segundo o desenho esquemático (Figura 6).

Conceitua-se restinga no sentido amplo, como um ecossistema litorâneo ocorrente nas planícies arenosas quaternárias, onde se desenvolvem diferentes comunidades vegetais (Araújo \& Henriques, 1984).

Este ecossistema compreende na região Amazônica uma área de $1.000 \mathrm{~km}^{2}$ (Pires, 1973), sendo freqüente ao longo do litoral Nordeste do Pará, na chamada "zona fisiográfica do salgado", apresentando características próprias conforme o trecho litorâneo.

Uma característica marcante desta restinga é a grande extensão da comunidade brejo herbáceo, situada logo após as faixas arenosas de dunas, podendo atingir extensões de até $200 \mathrm{~m}$. As espécies Sesuvium portulacastrum e Blutaparon portulacoides são as representantes da comunidade halófila, sendo as mesmas citadas por Costa Neto et al, (1995) para a referida comunidade na restinga do Crispim, Pará. Sporobolus virginicus, Fimbristylis cymosa, Canavalia rosea e Ambrosia microcephala superam em densidade relativa na comunidade psamófila reptante. No brejo herbáceo o destaque em densidade é atribuído principalmente a Fimbristylis spadicea. As espécies ocorrentes nesta amostragem são comuns noutras restingas do litoral nordeste paraense (Santos \& Rosário, 1988; Bastos et al., 1995; Bastos, 1996, Costa Neto, 1999; Amaral, 2001)

$\mathrm{O}$ número de comunidades vegetais de restinga varia ao longo do litoral brasileiro, podendo apresentar até 12 comunidades distintas, conforme registrado por Araújo \& Henriques (1984) no litoral fluminense. No Pará além das três comunidades citadas neste trabalho, outras três foram identificadas, denominadas de campo entre dunas, dunas, campo arbustivo aberto (ou campo de restinga) e mata de restinga (Bastos, 1996 e Costa Neto et al., 1995). 


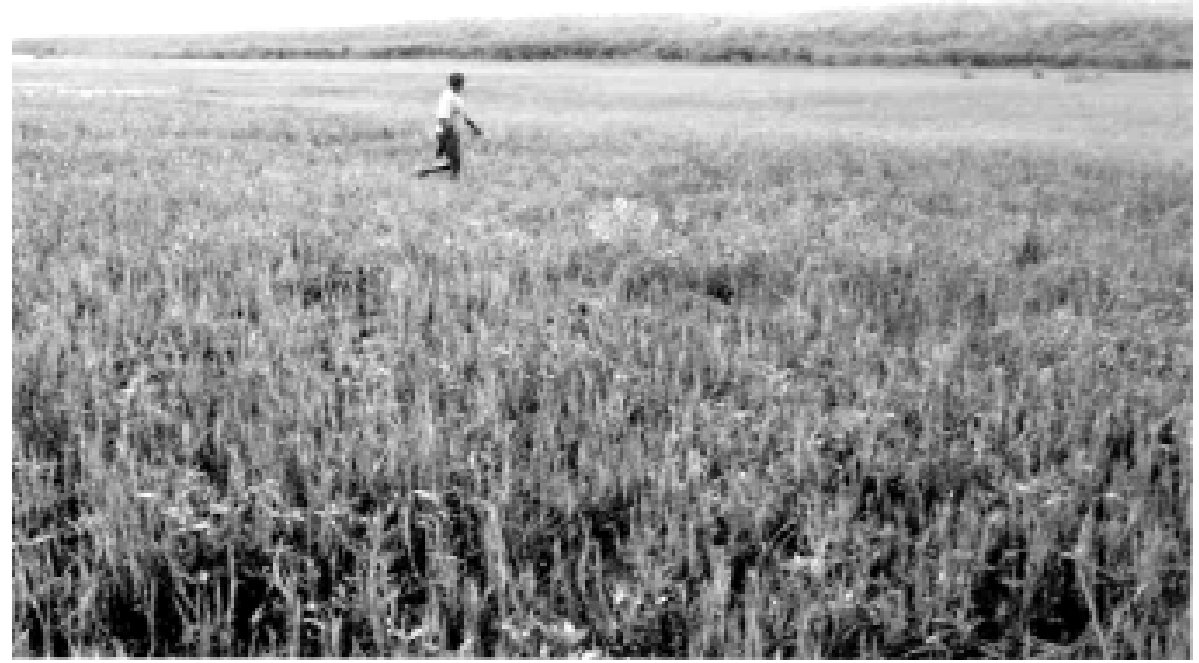

Figura 5 - Vista geral da restinga. Área de Proteção Ambiental Jabotitiua-Jatium, município de Viseu, Pará, Brasil.

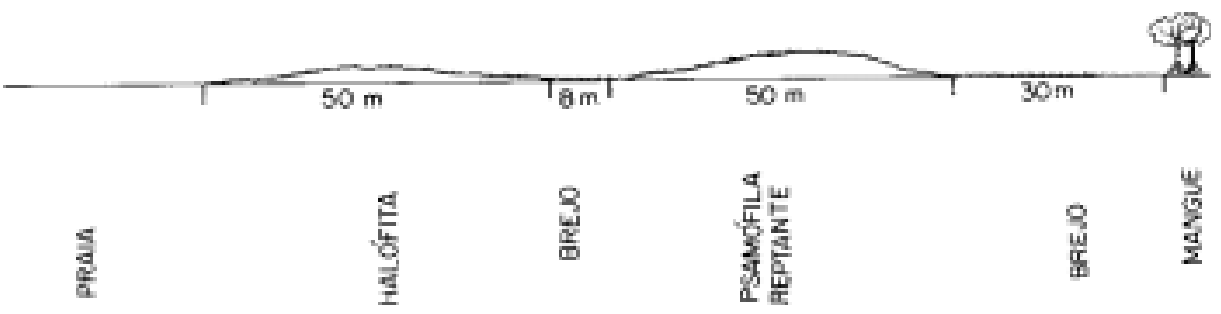

Figura 6 - Perfil esquemático da restinga da Área de Proteção Ambiental Jabotitiua-Jatium, município de Viseu, Pará, Brasil.

\section{CONSIDERAÇÕES FINAIS}

Dentre os quatro ecossistemas ocorrentes na APA, o manguezal ocupa maiores áreas, seguido do campo natural, da restinga e em menor dimensão a floresta mista com palmeiras. Inversamente a tal ordenamento, ocorre a riqueza em espécies, sendo superior na floresta mista com palmeiras (69), posteriormente a restinga (36), o campo natural (23) e finalmente o manguezal (4). Quanto a forma de vida, as ervas representam a maioria (48), seguida dos arbustos (38), árvores (34), Lianas (13), estipe (5) e epífitos (3).

A criação de APAs em ambientes costeiros na Amazônia, tem como objetivos principais, a conservação dos recursos bióticos e abióticos, com destaque, neste caso, à preservação de aves costeiras, como é o caso dos guarás (Eudocimus ruber) e de outras, inclusive as migratórias, a pesquisa científica, a educação ambiental e o ecoturismo, sem prejuízo das atividades de comunidades pesqueiras tradicionais.

De maneira geral, os ambientes componentes da APA apresentam-se preservados, contudo, faz-se necessário um controle sobre a atividade de criação de gado desenvolvida nos campos, bem como a exploração de madeira nas áreas de florestas para 
fins de construções de casas e cercas para o gado, de modo a não comprometer a estabilidade desses ambientes.

A APA em questão representa interessante laboratório para estudos da biodiversidade em áreas litorâneas, em função da considerável riqueza de espécies e as particularidades ambientais envolvidas, principalmente nos ambientes de campos naturais e floresta mista com palmeiras, onde pouco se conhece a respeito.

\section{AGRADECIMENTOS}

Ao técnico Luis Carlos Batista Lobato pelas identificações botânicas realizadas, ao Elielson Rocha pela confecção do perfil esquemático da restinga e ao Randy Evans pela versão em inglês do resumo.

\section{BIBLIOGRAFIA CITADA}

Almeida, S.S.; Lobato, L.C.B. 1990. Ecossistema de manguezal: uma abordagem sobre a presença humana, a flora e a fauna. Encontro de Ciências Sociais e o Mar, 4. Anais. Belém, jun. Museu Paraense Emílio Goeldi.

Almeida, S.S. 1996. Estrutura e florística em áreas de manguezais paraenses; evidências da influência do estuário amazônico. Boletim Museu Paraense Emílio Goeldi, Série Ciências da Terra, 8: 93-100.

Amaral, D.D. 1997. Contribuição ao Estudo das Formações Abertas de Moitas do Litoral Paraense. Restinga do Crispim, Município de Marapanim-PA. Dissertação de Mestrado, Universidade Federal do Pará/Museu Paraense Emílio Goeldi. 170p.

Amaral, D.D.; Santos, J.U.M.; Bastos, M.N.C.; Costa-Neto, S.V.; Costa, D.C.T. 2001. A vegetação da ilha Canela, Município de Bragança, Pará, Brasil. Bol. Mus. Para. Emílio Goeldi, sér. Bot., 17(2): 389-402.

Andrade, L.R.A, 1991. Análise da estrutura e composição específica das comunidades vegetais de moitas de restinga, Marica-RJ. Dissertação de Mestrado, Universidade de Brasília, 94p.
Araújo, D.S.D.; Henriques, R.P.B., 1984. Análise florística das restingas do Estado do Rio de Janeiro. In: Restingas: Origem, Estrutura e Processos. Lacerda, L.D. et al. (orgs.). Niterói, CEUFF, p.159-193.

Bastos, M.N.C., 1984. Levantamento florístico dos campos do Estado do Pará. I - Campos de Joanes, Ilha do Marajó-Pará. Bol. Mus. Para. Emílio Goeldi, sér. Bot., 1(1/ 2): 67-86.

Bastos, M.N.C.; Rosário, C.S.; Lobato, L.C.B. 1995. Caracterização fitofisionômica da restinga de Algodoal, Maracanã-PA, Brasil. Bol. Mus. Para. Emílio Goeldi, sér Bot., 11 (2): 173-197.

Bastos, M.N.C., 1996. Caracterização das formações vegetais da restinga $d a$ Princesa, Ilha de Algodoal-PA. Tese de Doutorado, Universidade Federal do Pará/ Museu Paraense Emílio Goeldi. 249p.

Bastos, M.N.C.; Lobato, L.C.B. 1996. Estudos fitossociológicos em áreas de bosque de mangue na praia do Crispim e ilha de Algodoal, Pará. Bol. Mus. Para. Emílio Goeldi, sér. Ciênc. Terra, 8: 157-167.

Costa-Neto, S.V.; Bastos, M.N.C.; Lobato, L.C.B., 1995. Composição florística e fitofisionomia da restinga do Crispim, município de Marapanim, PA. Bol. Mus. Para. Emílio Goeldi, Sér. Bot., 11(1).

Costa-Neto, S.V. 1999. As formações herbáceas da restinga do Crispim, Marapanim - Pará. Dissertação de mestrado, Faculdade de Ciências Agrárias do Pará. 128 p.

Costa-Neto, S.V.; Pereira, J.O; Bastos, M.N.C.; Santos, J.U.M.; Amaral, D.D. 2001. Fitossociologia das formações herbáceas da restinga do Crispim, Marapanim, Pará. Bol. Mus. Para. Emílio Goeldi, sér. Bot., 17(1): 161-186.

Cronquist, A. 1981 An integrated system of classification of flowering plants. New York: Columbia University Press., 1261p.

Diegues, A.C., 1987, Conservação e desenvolvimento sustentado de ecossistemas litorâneos do Brasil. In: Simpósio sobre Ecossistema da Costa Sul 
e Sudeste Brasileira. Cananéia. ACIESP, 3: 196-243.

Instituto Brasileiro de Desenvolvimento Florestal (IBDF), 1988. Alteração da cobertura vegetal do Estado do Pará. Relatório Técnico, Belém, IBDF/PMCFD. $28 \mathrm{p}$.

Lisboa, P.L.B., Lisboa, R.C.L., Rosa, N.A.; Santos, M.R. 1993. Padrões de diversidade florística na reserva ecológica do Bacurizal, em Salvaterra, ilha do Marajó, Pará. Bol. Mus. Para. Emílio Goeldi, sér. Bot., 9(2): 223-248.

MPEG, 1998. Caracterização da fitoecologia e da flora da zona de influência da hidrovia do Marajó, ilha do Marajó, Estado do Pará Relatório Técnico. 51p.

Pires, J.M. 1973. Tipos de Vegetação da Amazônia, In: O Museu Goeldi no ano do sesquicentenário. Belém, MPEG (Publ. Avulsas, 20), p. 179-202.
Prost, M.T.R. da C. 1994. O Litoral Nordeste do Estado do Pará: Dinâmica atual e aplicações do sensoriamento remoto. Municípios de Marapanim, Maracanã e Salinópolis. Programa: evolução atual e Holocênica do litoral Nordeste do Pará. Relatório, Belém, CNPq, 55p.

Santos, J.U.M.; Rosário, C. S. 1988. Levantamento da vegetação fixadora de dunas de Algodoal-PA. Belém. Bol. Mus. Para. Emílio Goeldi, sér. Bot., 4 (1): 133-151.

Schaeffer-Novelli, Y.; Cintrón, G. 1988. Expedição Nacional aos Manguezais do Amapá, ilha de Maracá. Relatório Técnico - Cons. Nac. Desenv. Científico e Tecnológico-CNPq., Coordenação de Ciências Biológicas. 99p.

The Nature Conservancy (TNC). 1992. Rapid ecologic evaluation. Washington, D.C, $207 \mathrm{p}$. 
